\title{
Attitudes of pregnant women and mothers of children with orofacial clefts toward prenatal diagnosis of nonsyndromic orofacial clefts in a semiurban set-up in India
}

\author{
Poornima Kadagad, Pascal Pinto, Rajesh Powar ${ }^{1}$ \\ Department of Oral and Maxillofacial Surgery, KLE VK Institute of Dental Sciences, ${ }^{1}$ Department of Plastic Surgery, JN Medical \\ College, KLE University, Belgaum, Karnataka, India
}

Address for correspondence: Dr. Poornima Kadagad, Room No. 5, Department of Oral and Maxillofacial Surgery KLE VK Institute of Dental Sciences, Belgaum - 590010, Karnataka, India

\section{ABSTRACT}

Objectives: To assess the attitudes of pregnant women and mothers of children with orofacial clefts toward prenatal diagnosis of clefts and elective termination of pregnancy, and to investigate their opinion about who makes reproductive decisions in the family. Design: Two hundred subjects were included in the study prospectively regarding hypothetical prenatal ultrasound diagnosis of clefts. Setting: The study was done in a private tertiary care institution and a teaching hospital. Subjects/Participants: One hundred pregnant women consulting the Obstetrics department and 100 mothers of children with orofacial clefts in the Cleft and Craniofacial Unit were selected. Materials and Methods: Group I subjects were interviewed using a questionnaire and were shown preoperative and postoperative pictures of children treated for cleft lip and palate. Group II subjects were interviewed using a questionnaire. Results: Only $3 \%$ of Group I subjects and $2 \%$ of Group II opined that they would choose the elective termination of pregnancy if the fetus was diagnosed with a cleft on an ultrasound scan. In Group II, 70\% subjects wished to have known about pregnancy affected with cleft prenatally and $96 \%$ said they would definitely avail ultrasound scans to determine pregnancy affected by clefts in future. Conclusions: Majority of the respondents from both the groups chose to continue with the pregnancy affected with a cleft when questioned regarding hypothetical prenatal ultrasound diagnosis of the cleft.

\section{KEY WORDS}

Orofacial clefts, prenatal ultrasound diagnosis, termination of pregnancy

\begin{tabular}{|l|l|}
\hline \multicolumn{2}{|c|}{ Access this article online } \\
\hline Quick Response Code: & Website: \\
\hline & www.ijps.org \\
\cline { 2 - 2 } & DOI: \\
\hline
\end{tabular}

\section{INTRODUCTION}

acial deformity, especially around the mouth, is
rated as the least attractive of all deformities..$^{11,2]}$
Orofacial cleft is one such condition which affects
lip, alveolus, and hard and soft palate either unilaterally
or bilaterally. Though comprehensive treatment for an 
orofacial cleft is now available universally, an increased awareness of cosmetic appearance in society and the availability of prenatal ultrasound diagnosis have led to evidence of elective termination of pregnancy. ${ }^{[3,4]}$ Since non-syndromic orofacial clefts are nonlethal birth defects, prenatal ultrasound diagnosis and subsequent termination of pregnancy is an important ethical issue. ${ }^{[5,6]}$

Transvaginal sonography due to its high resolution and proximity to the fetus can detect $95 \%$ of fetal malformations at 14-16 weeks of gestation. ${ }^{[7-10]}$ The detection of orofacial clefts is being routinely included in ultrasound screening practices in some countries ${ }^{[11,12]}$ and providing reproductive choices to pregnant women is one of the objectives of such fetal anomaly screening programmes. ${ }^{[13]}$ The availability of this advanced technology in the Indian subcontinent can offer reproductive choices to pregnant women who were hitherto unexposed to the prenatal diagnosis of clefts. $^{[14]}$ The elective termination of pregnancy for prenatal diagnosis of a non-syndromic oral cleft has been viewed differently across the world, the concerns being ethical, religious, and cultural differences among the population. ${ }^{[15,16]}$

The incidence of terminations of pregnancy for nonsyndromic facial clefts because of prenatal diagnosis ranges from $0 \%$ to $92 \%$ whereas the rate of termination is high when the cleft is associated with other malformations. ${ }^{[18-20]}$ The attitude of the Indian population toward individuals affected by clefts is not discriminative as the acceptance of cosmetically deprived patients is high in contrast to the population of developed countries where the practice of elective termination of pregnancy is prevalent. ${ }^{[4]}$ To our knowledge, no previous studies have been conducted in the Indian subcontinent to assess the perceptions about the prenatal ultrasound diagnosis of orofacial clefts and the option of elective termination of pregnancy in our population. A study was designed to assess the attitudes of pregnant women and mothers of children with orofacial clefts toward a hypothetical situation of prenatal ultrasound diagnosis of clefts and elective termination of pregnancy and passed through our ethical committee. Though hypothetical, this study is important to determine future treatment needs in our country where every year 30,000 babies are born with orofacial clefts. ${ }^{[2]]}$

\section{MATERIALS AND METHODS}

Our center is a tertiary teaching hospital with 2000 beds catering to the needs of a population of 1.5 million. The
Cleft and Craniofacial Unit was established in year 2001 and since then 5000 patients with cleft lip and palate have been managed successfully. It consists of a multidisciplinary team of a cleft surgeon, orthodontist, pediatrician, anesthesiologist, speech therapist, trained nurse, and social worker. The study consisted of 200 patients who were divided into 2 groups. Pregnant women reporting to the Obstetrics outpatient department of the hospital were randomly assigned to Group I and inclusion criteria for Group I was all pregnant women in the first and second trimesters. Group II consisted of mothers of children with an orofacial cleft reporting to the Cleft and Craniofacial Unit. These subjects were randomly enrolled in the study between November 2009 and May 2010. Inclusion criteria for subjects in Group II were mothers of children primarily operated for cleft lip, cleft palate, and cleft lip and palate both. All the subjects were interviewed in the outpatient department of Obstetrics and Cleft and Craniofacial Unit for Groups I and II, respectively, using a structured questionnaire and also demographic information by a single interviewer in subjects' vernacular language. Informed consent was taken from all the subjects and they were encouraged to answer the questions and were also counseled regarding the etiology and treatment of clefts. Ethical clearance was obtained from institution's Ethical Council.

The questionnaire devised was intended to collect the information regarding the literacy level, occupation of spouse, caste and religion, and whether they live in a joint family or nuclear family. The intention was to acquire data that might influence decision making when confronted with the situation of having a child affected with cleft lip palate. The study was piloted earlier on 10 subjects from both the groups so that ambiguous questions were modified.

\section{RESULTS}

Table 1 represents the demographic data of the subjects enrolled in Groups I and II of the study. In Group I, $82 \%$ of subjects were less than 25 years of age, $87 \%$ were educated, being high school graduated or more, $92 \%$ were housewives, $75 \%$ of subjects' husbands were self-employed in a small business, and $21 \%$ were farmers implying that almost $96 \%$ belonged to the lower socioeconomic stratum; $95 \%$ of the subjects studied were Hindu and $85 \%$ of them lived in joint families.

In Group II, 76\% of children with cleft lip palate were under 2 years of age; $96 \%$ were diagnosed as non-syndromic oral 
Table 1: Sociodemographic data of Group I and Group II respondents

\begin{tabular}{|c|c|c|}
\hline Characteristic & Group I & Group II \\
\hline \multicolumn{3}{|c|}{ Respondents' age (years) } \\
\hline $18-20$ & 24 & \\
\hline $21-25$ & 56 & \\
\hline $26-30$ & 15 & \\
\hline $31-35$ & 5 & \\
\hline$>35$ & 0 & \\
\hline \multicolumn{3}{|l|}{ Education } \\
\hline$\leq 7$ th grade & 7 & 20 \\
\hline 8th-10th grade & 54 & 25 \\
\hline 11th12th grade & 25 & 9 \\
\hline Graduate & 9 & 10 \\
\hline Illiterate & 5 & 36 \\
\hline \multicolumn{3}{|l|}{ Occupation } \\
\hline Housewife & 92 & 73 \\
\hline Employed & 8 & 27 \\
\hline \multicolumn{3}{|c|}{ Spouse's occupation } \\
\hline Agriculture & 21 & 44 \\
\hline Self-employed & 75 & 16 \\
\hline Professional & 4 & 40 \\
\hline \multicolumn{3}{|l|}{ Religion } \\
\hline Hindu & 95 & 89 \\
\hline Muslim & 5 & 10 \\
\hline Christian & & 1 \\
\hline \multicolumn{3}{|l|}{ Type of family } \\
\hline Joint family & 85 & 69 \\
\hline Nuclear family & 15 & 31 \\
\hline \multicolumn{3}{|l|}{ Area of residence } \\
\hline Rural & 60 & 66 \\
\hline Semiurban & 40 & 34 \\
\hline
\end{tabular}

clefts. Seventy-four percent of respondents were post-high school educated; $44 \%$ were farmers and $40 \%$ employed as laborers. A total of $89 \%$ were Hindus; $73 \%$ of mothers were housewives and $69 \%$ of them lived in joint families. Hundred percent of the subjects in both the groups were from rural and semiurban areas.

Table 2 presents the responses of the subjects to the hypothetical question on their attitude toward the prenatal ultrasound diagnosis of cleft lip and palate. Three percent subjects in Group I and 2\% in Group II chose the option of medical termination of pregnancy. A total of $70 \%$ of Group II subjects wished they had known about the prenatal diagnosis of cleft and $71 \%$ expressed that prenatal ultrasound diagnosis is important. Only 1\% in Group I and 6\% in Group II subjects expressed that they would be the sole decision maker in the family for reproductive choices in the context of pregnancy detected with a cleft fetus.

\section{DISCUSSION}

With the increasing awareness regarding the availability of the comprehensive treatment for cleft lip and palate in
Table 2: Responses of Group I and Group II

\begin{tabular}{lcc}
\hline Question & Group I & Group II \\
\hline Choice of reproduction if prenatal & & \\
ultrasonography revealed a fetus with a & & \\
cleft & 94 & 96 \\
$\quad$ Continue pregnancy & 3 & 2 \\
$\quad$ Medical termination of pregnancy & 3 & 2 \\
$\quad$ Refused to answer & & \\
Importance of knowing the diagnosis of a & & \\
cleft prenatally & 62 & 24 \\
Extremely important & 29 & 51 \\
Important & 9 & 20 \\
Somewhat important & 0 & 5 \\
Not important & & \\
Decision maker in the family & 1 & 6 \\
Respondent herself & 37 & 35 \\
Father of the child & 34 & 37 \\
Elders/in-laws at home & 20 & 2 \\
Combined (all together) & 5 & 20 \\
Father and mother of the child & 3 & 0 \\
Refused to answer & & \\
Had known diagnosis prenatally & & 9 \\
Yes & & 91 \\
No & & \\
Wished to have known prenatally & & 13 \\
Yes & & \\
No & & \\
Not sure & & \\
\hline
\end{tabular}

developing countries due to better access to health care and a desire to have an aesthetically perfect child, various non-governmental organizations have been successful in rendering free cleft services in these countries. ${ }^{[22]}$

The rationale for including mothers in the study was to assess the attitudes of women in particular in both groups toward the prenatal diagnosis of clefts and their opinion about who will be the decision maker in the context of the prenatal ultrasound diagnosis of a cleft. Studies have shown that the role of women in decision making in pregnancy and abortion was undersized ${ }^{[23]}$ and their husbands and in-laws had a greater role in decision making. ${ }^{[24]}$ In this study, when pregnant women and mothers of children with a cleft were hypothetically questioned regarding their choice of reproductive option if prenatally diagnosed to have a cleft fetus, only $3 \%$ of pregnant women and $2 \%$ of mothers of children with a cleft chose to electively terminate the pregnancy.

A study by Bronshtein and Blumenfeld ${ }^{[25]}$ in Israel showed that 14 out of 15 patients voluntarily terminated pregnancy when a cleft was diagnosed by prenatal ultrasound. This is notable in that all the 15 couples had consulted parents of children with a cleft who had undergone surgical repair. In the follow-up of the same 
study, authors ${ }^{[26]}$ quoted out that of 24 patients diagnosed for the cleft, 23 chose to terminate the pregnancy. In our study, the subjects were shown pre and postoperative pictures of the child with cleft lip palate, and the responses of the pregnant women were to a hypothetical question that in case their ultrasound scan diagnosed a cleft, what reproductive choice they would make. However, in the published studies, ${ }^{[25,26]}$ the subjects were pregnant women who were actually diagnosed with fetal cleft lip and palate by ultrasound. The responses might be subjective for the simple reason that the decision varies when one actually has to face a situation than when one hypothetically reacts to a situation.

The responses of mothers of children with clefts to the same question are similar to the results of a study conducted in Argentina by Wyszynski, Perandones, and Bennum ${ }^{[16]}$ wherein most parents of children with a cleft strongly support the continuation of pregnancy as they felt that an oral cleft is not a serious condition requiring the termination of pregnancy and only $6.4 \%$ of 165 parents chose to terminate pregnancy. The reason for the continuation of pregnancy with a cleft child in Argentina is explained on the basis that most subjects in the study were Catholics and abortion is legally restricted in Argentina. The reasons for similar results in our study may be attributed to cultural and religious beliefs in this region. ${ }^{[27]}$

In both the groups, the main decision maker in the family was found to be either the husband of the woman or the elders/in-laws at home. Though these women are educated and aware of the cleft condition, majority of them live in joint families where the head of the family makes the decisions. An extensive study conducted by Alok Ranjan ${ }^{[28]}$ on the institutional context of fertility and reproductive health in Madhya Pradesh, India, highlights the institutional environment - the family, the society, the culture and tradition, etc. - in which people have strong bearings on reproductive health decision making and hence on fertility and reproductive health outcomes.

Majority of the subjects in both groups of our study felt that it was important for them to know and become aware of conditions like cleft prenatally. Some subjects opined that being aware of conditions prior to child birth makes one capable of handling such situation better when actually confronted. Few of the subjects in Group II expressed the concern that though they underwent ultrasound scans during pregnancy, the obstetrician might not have informed them about the diagnosis prior to birth.
Several studies have revealed that prenatal counseling about the cleft is thought to give the family an opportunity to learn about clefts and become prepared for the event and our study strongly supports the importance of prenatal diagnosis. Parents may be counseled about how the immediate needs of their newborn will differ from infants born without an orofacial cleft. Parents will have time to prepare by talking with health care providers, family members, and tapping multiple resources to learn more about orofacial clefts. ${ }^{[29-33]}$

In contrast, some questions remain as to whether the early knowledge of a pregnancy with a cleft child may generate greater maternal anxiety during a presumably joyful period, whether prenatal information is of any value because the problem cannot be corrected prenatally, ${ }^{[34]}$ and whether prenatal diagnosis might encourage the termination of the pregnancy in the absence of other malformations. ${ }^{[35]}$ However, it emphasizes the need of prenatal counseling to pregnant women subsequent to prenatal diagnosis of cleft lip and palate.

The differences noted in our study can be contributed to many factors, the most important one being the eastern family values like more emphasis on deeds than appearance and acceptance of physically deprived individuals and the law of karma. ${ }^{[36]}$ It may also be attributed to facts like lower education and awareness level, and lack of advanced health care access and reproductive choices. ${ }^{[37]}$ We did not compare the two groups in our study as the groups are not matched and hence not comparable but in spite of these demographic differences, it is noteworthy that the attitude of two sets of mothers toward the prenatally diagnosed cleft baby remains essentially the same which goes to suggest the general attitude of our society. Our study is the representative of a particular socioeconomic group. A larger sample size of a different socioeconomic class is required to assess the attitudes toward the prenatal ultrasound determination of pregnancy with a cleft child. It would be prudent to conduct studies in actual pregnant women diagnosed with a cleft fetus.

The attitude of pregnant women and mothers of children with clefts would seem to indicate that, unlike studies in developed nations, the trend of accepting a child with an abvious congenital anomaly is far higher in our society. And this tolerance is expected in a civilization as ancient and as enriched as ours, which has always cherished deeds and values and treated appearance as rather trivial in comparison. 


\section{REFERENCES}

1. Lansdown R. Psychological problems of patient with cleft lip and palate: Discussion paper. J Royal Soc Med 1990;83:448-50.

2. Harper DC, Peterson DB. Children of the Philippines, Attitudes toward Visible Physical Impairment. Cleft Palate Craniofac J 2001;38:566-76.

3. Forrester MB, Merz RD, Yoon PW. Impact of prenatal diagnosis and elective termination on the prevalence of selected birth defects in Hawaii. Am J Epidemiol 1998;148:1206-11.

4. Bromage DI. Prenatal diagnosis and selective abortion: A result of the cultural turn? Med Humanit 2006;32:38-42.

5. Macer DR. (1998b). Ethics and Prenatal Diagnosis. In: Milunsky A, editor. Genetic Disorders and the Fetus: Diagnosis, Prevention and Treatment. Baltimore: John Hopkins University Press; 1998. p. 999-1024.

6. Bouchard L, Renaud M, Kremp O, Dallaire L. Selective abortion: A new moral order? Consensus and debate in the medical community. Int J Health Serv 1995;25:65-84.

7. Bronshtein M, Blumenfeld I, Kohn J, Blumenfeld Z. Detection of cleft lip and palate by early second trimester transvaginal sonography. Obstet Gynecol 1994;84:73-6.

8. Bronshtein M, Yoffe N, Zimmer E, Blumenfeld Z. Early detection of fetal anomalies by transvaginal sonography. Fetal Matern Med Rev 1993;5:137-46.

9. Gullino E, Serra M, Ansaldi C, Massobrio M, Pagliano M. Bilateral cleft lip and palate diagnosed sonographically at 11 weeks of pregnancy. J Clin Ultrasound 2006;34:398-401.

10. Kurjak A, Azumendi G, Andonotopo W, Salihagic-Kadic A. Three- and four-dimensional ultrasonography for the structural and functional evaluation of the fetal face. Am J Obstet Gynecol 2007;196:16-28.

11. Moore J, Bhide A. Ultrasound prenatal diagnosis of structural abnormalities. Obstet Gynaecol Reprod Med 2009;19:333-8.

12. Salomon LJ, Alfirevic Z, Berghella V, Bilardo C, Hernandezandrade $\mathrm{E}$, Johnsen SL, et al. Practice guidelines for performance of the routine mid-trimester fetal ultrasound scan. Ultrasound Obstet Gynecol (2010). [Last accessed on 2011 Apr 03].

13. Donna Kirwan and the NHS Fetal Anomaly Screening Programme (NHS FASP) NHS Fetal Anomaly Screening Programme. Available from: http://www.Fetalanomaly.Screening.Nhs.Uk/ Standardsandpolicies. [Last accessed on $2011 \mathrm{Apr}$ 03].

14. Bhattacharya S. Editorial: Winds of change: Hope for cleft lip and palate patients. Indian J Plast Surg 2009;42:1.

15. Zahed L, Nabulsi M, Tamim H. Attitudes towards prenatal diagnosis and termination of pregnancy among health professionals in Lebanon. Prenat Diagn 2002;22:880-6.

16. Wyszynski DF, Perandones C, Bennun RD. Attitudes toward prenatal diagnosis, termination of pregnancy, and reproduction by parents of children with nonsyndromic oral clefts in Argentina. Prenat Diagn 2003;23:722-7.

17. Johnson N, Sandy JR. Prenatal diagnosis of cleft lip and palate. Cleft Palate Craniofac J 2003;40:186-9.

18. Li Z, Ren A, Liu J, Zhang L, Ye R, Li S, et al. High prevalence of orofacial clefts in Shanxi province in Northern China, 2003-2004. Am J Med Genet A 2008;146A:2637-43.

19. Russel KA, Allen VM, Macdonald ME, Smith K, Dodds L. A population based evaluation of antenatal diagnosis of orofacial clefts. Cleft Palate Cranifac J 2008;45:148-53.

20. Vallino-Napoli LD, Riley MM, Halliday JL. An epidemiologic study of orofacial clefts with other birth defects in Victoria, Australia.
Cleft Palate Craniofac J 2006;43:571-6.

21. Mossey P, Little J. Addressing the challenges of cleft lip and palate research in India. Indian J Plast Surg 2009;42 Suppl:S9-S18.

22. Singh SK. Smile Train: The ascendancy of cleft care in India. Indian J Plast Surg 2009;42:192-8.

23. Gupte M, Bandewar S, Pisal H. Women's Role in Decision Making in Abortion: Profiles from Rural Maharashtra. CEHAT (Unpublished document). Available from: http://www.Womenstudies.In/Elib/ Abortion/Ab_Womens_Role.Pdf. [Last accessed on 2011 Apr 03].

24. Singh A, Arora AK. How much do Rural Indian Husbands Care for the Health of their Wives. Indian J Community Med 2008;33:19-25.

25. Bronshtein M, Blumenfeld I, Blumenfeld Z. Early prenatal diagnosis of cleft lip and its potential impact on the number of babies with cleft lip. Br J Oral Maxillofac Surg 1996;34:486-7.

26. Blumenfeld Z, Blumenfeld I, Bronshtein M. The Early prenatal diagnosis of cleft lip and the decision making process. Cleft Palate Craniofac J 1999;36:105-7.

27. Chattopadhyay S, Simon A. East meets West: Cross-cultural perspective in end-of-life decision making from Indian and German viewpoints. Med Health Care Philos 2008;11:165-74.

28. Chaurasia AR. The Institutional Context of Fertility and Reproductive Health in Madhya Pradesh, India. Centre for Studies in Demography and Ecology University of Washington Seattle, WA. 98105. Available from: http://www.csde.washington.edu/ downloads/00-7.pdf. [Last accessed on 2011 Apr 11].

29. Nusbaum R, Grubs RE, Losee JE, Weidman C, Ford MD, Marazita $M L$. A qualitative description of receiving a diagnosis of clefting in the prenatal and postnatal period. J Genet Couns 2008;17:336-50.

30. Robbins JM, Damiano P, Druschel CM, Hobbs CA, Romitti PA, Austin AA, et al. Prenatal diagnosis of orofacial clefts: Association with maternal satisfaction, team care, and treatment outcomes. Cleft Palate Craniofac J 2010;47:476-81.

31. Jones M. Prenatal Diagnosis of Cleft Lip and Palate: Detection Rates, Accuracy of Ultrasonography, Associated Anomalies, and Strategies for Counseling. Cleft Palate Craniofac J 2002;39: 169-73.

32. Andrews-Casal M, Johnston D, Fletcher J, Mulliken JB, Stal S, Hecht JT. Cleft lip with or without cleft palate: Effect of family history on reproductive planning, surgical timing and parental stress. Cleft Palate Craniofac J 1998;35:52-7.

33. Davalbhakta A, Hall PN. The impact of antenatal diagnosis on the effectiveness and timing of counselling for cleft lip and palate. $\mathrm{Br} \mathrm{J}$ Plast Surg 2000;53:298-301.

34. Matthews MS, Cohen M, Viglione M, BrownAS. Prenatal counseling for cleft lip and palate. Plast Reconstr Surg 1998;101:1-5.

35. Weatherley-White RC, Eiserman W, Beddoe M, Vanderberg R. Perceptions, expectations, and reactions to cleft lip and palate surgery in native populations: A pilot study in rural India. Cleft Palate Craniofac J 2005;42:560-4.

36. Klein T, Pope AW, Getahun E, Thompson J. Mothers' reflections on raising a child with a craniofacial anomaly. Cleft Palate Craniofac J 2006;43:590-7.

37. Bakheit AM, Shanmugalingam V. A study of the attitudes of a rural Indian community toward people with physical disabilities. Clin Rehabil 1997;11:329-3.

How to cite this article: Kadagad P, Pinto P, Powar R. Attitudes of pregnant women and mothers of children with orofacial clefts toward prenatal diagnosis of nonsyndromic orofacial clefts in a semiurban set-up in India. Indian J Plast Surg 2011;44:489-93.

Source of Support: Nil, Conflict of Interest: None declared. 